\title{
Forecast experiment on the Kamaishi repeating earthquakes based on numerical simulations using friction law
}

\author{
Shingo Yoshida*, Naoyuki Kato and Jun'ichi Fukuda
}

\begin{abstract}
Repeating M5-class earthquakes occurred with a regular recurrence interval on the plate boundary offshore Kamaishi before the 2011 M9 Tohoku-oki earthquake. Since this event, 11 repeating events of M5-M6 have occurred with shorter recurrence intervals than before the $M 9$ event. We performed a forecast experiment on the Kamaishi repeaters after the Tohoku-oki earthquake based on numerical simulations assuming a large patch containing a small patch on a fault model that undergoes continuous afterslip. Simulations were conducted for various parameter values to produce time history of repeated ruptures. To forecast the Ith event, we selected several modeled sequences that are able to accurately reproduce the observed event sequence up to the $(I-1)$ th event. The averages of the occurrence times and magnitudes over the selected sequences were used as ensemble forecasts. We attempted to predict the 7 th event to the 11 th event and discussed the obtained forecast spreads and errors.
\end{abstract}

Keywords: Kamaishi repeating earthquakes, Forecast experiment, Afterslip, The 2011 Tohoku-oki earthquake

\section{Introduction}

Repeating M5-class earthquakes on the plate boundary offshore Kamaishi occurred with a regular recurrence intervals before the 2011 M9 Tohoku-oki earthquake (Matsuzawa et al. 2001, 2002; Uchida et al. 2005) as denoted by circle in Fig. 1. Uchida et al. (2014) reported that an M6-class event occurred immediately after this $M 9$ event and was followed by $M 5$-class events at shorter intervals than before the $M 9$ event. To explain the expansion of the seismic slip area under the high loading rates after the $M 9$ event, they proposed a conceptual fault model as that contains conditionally stable regions. Before the $M 9$ event, the conditionally stable regions are characterized by aseismic slip, whereas seismic slip occurs only in the unstable region, resulting in regular occurrence of the repeating earthquakes. After the $M 9$ event, aseismic-to-seismic transition in the surrounding region was caused by the afterslip, and the seismic slip occurred in the whole area, resulting in an $M$ 6-class

*Correspondence: shingo@eri.u-tokyo.ac.jp Earthquake Research Institute, University of Tokyo, 1-1-1 Yayoi, Bunkyo-ku, Tokyo 113-0032, Japan event. Using this model, Yoshida et al. (2015) conducted numerical simulations of the Kamaishi repeaters assuming the afterslip estimated from GPS data by Fukuda et al. (2013). In this simulation, an M6-class event occurring immediately after the $M 9$ event was reproduced, and the calculated occurrence times of the simulated subsequent repeaters resembled those of the observed repeaters to some degree. In this study, we performed a forecast experiment on the Kamaishi repeaters occurring after the M9 event based on Case 3 model by Yoshida et al. (2015) in which a large parch contains a small patch.

Numerous studies have been conducted on the statistical forecasting of earthquakes. For example, Okada et al. (2012) conducted a probabilistic forecast for small repeating earthquakes along the Japan Trench. However, there are few studies on forecasts based on numerical simulations. Kano et al. (2013) developed an adjoint data assimilation method to estimate the frictional parameters on a fault with the objective of predicting earthquakes triggered by afterslip propagation. Using synthetic data generated by simulations, they tested the feasibility of such prediction. Kano et al. (2015) estimated the frictional parameters for the afterslip of the 


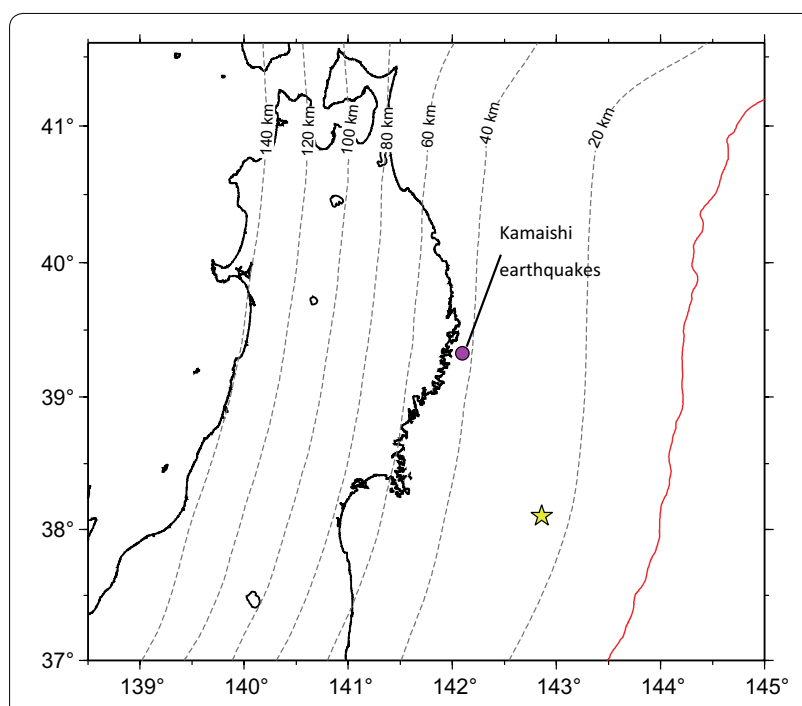

Fig. 1 Epicenters of the Kamaishi repeating earthquakes (circle) and the 2011 M9 Tohoku-oki earthquake (star)

2003 Tokachi-oki earthquake using a data assimilation technique and the data obtained up to 15 days after the main shock. On the basis of their results, they calculated the afterslip during days 16-30 and compared it with the observed afterslip. Kato (2004a) and Kuroki et al. (2004) examined the effects of nearby earthquakes on the occurrence time of large interplate earthquakes based on numerical simulations.

Since the $M 9$ event, 11 events have occurred in the Kamaishi sequence, as shown in Fig. 2. Hereafter, the events occurring after the $M 9$ event are labeled B1-B11 in the order of occurrence, and those before the $M 9$ event labeled $A$. Events B1-B9 were analyzed by Uchida et al. (2014), and events B10 and B11 were reported by the Japan Meteorological Agency (http://www.data.jma. go.jp/svd/eqev/data/gaikyo/monthly). We conducted numerical simulations by various sets of parameter.
Unlike Yoshida et al. (2015) where only one example for Case 3 model is provided without showing how the results change with frictional parameters, in the present paper, we try to search for a proper combination of model parameters that well explain the observed sequence. To forecast the Ith event in this study, several modeled sequences that are able to accurately reproduce the observed occurrence times up to the $(I-1)$ th event were selected. The average of the occurrence times of the $I$ th event in the selected sequences then yields an ensemble forecast. This paper considers how the sequences should be selected and discusses forecast errors.

\section{Numerical simulation model}

In this section, we briefly explain the model used in the numerical simulation; a detailed explanation can be found in Yoshida et al. (2015). We consider the twodimensional planar fault model proposed by Kato (2003, 2004b) as shown in Fig. 3. The fault model is loaded at a constant plate velocity $V_{\mathrm{pl}}$ in the $x$-direction before an afterslip due to the 2011 M9 Tohoku-oki earthquake. The shear stress $\tau_{\mathrm{zx}}$ and slip $u$ in the $x$-direction are considered, and $\tau_{z x}$ is expressed as $\tau$ for simplicity. The fault plane is divided into many square cells with equal areas. The shear stress on cell $(i, j)$ is given by

$\tau(i, j)=\sum_{k, l} K(i-k, j-l)\left[u(k, l)-V_{\mathrm{pl}} t\right]-\frac{G}{2 \beta} V(i, j)$

where $K(i-k, j-l)$ is the static shear stress at the center of cell $(i, j)$ due to the uniform unit slip in the $x$-direction over the cell $(k, l), u(k, l)$ is the slip at the cell $(k, l)$, $V=\mathrm{d} u / \mathrm{d} t$ is the slip rate, and $\beta$ is the $\mathrm{S}$ wave speed. In the simulations, $V_{\mathrm{pl}}=0.085 \mathrm{~m} /$ year (DeMets et al. 1990), $G=50 \mathrm{GPa}$, Poison's ratio $=0.25$ and $\beta=4.2 \mathrm{~km} / \mathrm{s}$. The second term on the right-hand side of Eq. (1) represents the approximate shear stress reduction due to
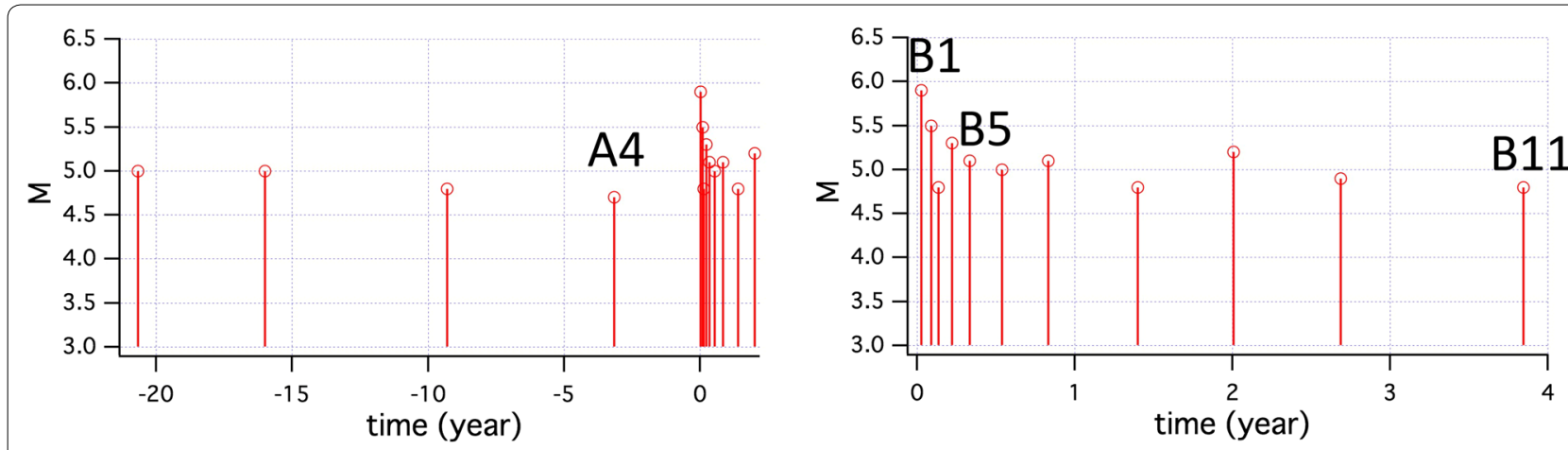

Fig. 2 Magnitude-time plot of the Kamaishi repeating earthquake sequence, redrawn based on Uchida et al. (2014). $t=0$ is taken as the occurrence time of the 2011 M9 Tohoku-oki earthquake. In the right-hand panel, the sequence after the M9 event is shown with an expanded time axis. The event occurring after the M9 event are labeled B1-B11 in the order of occurrence, and those before the $M 9$ event labeled $A$ 


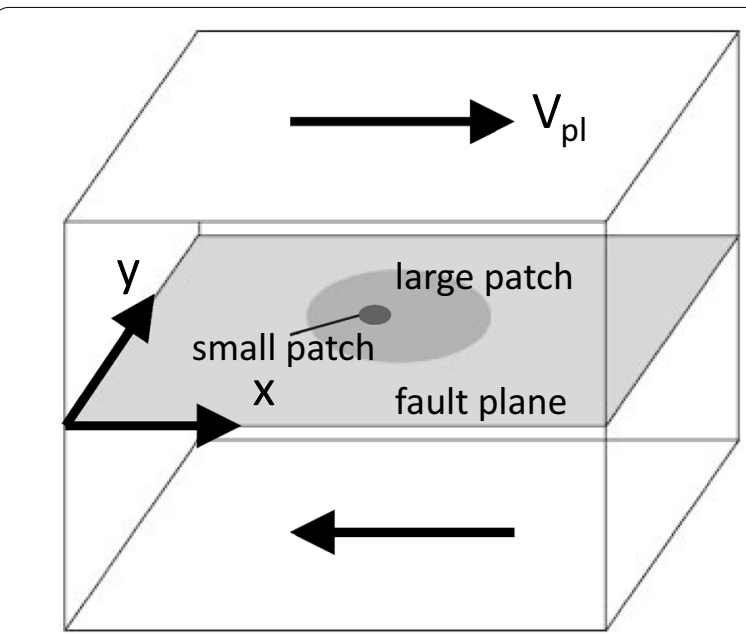

Fig. 3 Two-dimensional planar fault model on the xy plane. The fault is loaded in the $x$-direction. A large patch contains a small patch

wave radiation, which was introduced by Rice (1993). The convolution in Eq. (1) is evaluated by two-dimensional FFT assuming the periodic boundary condition. In this procedure, $\tau(i, j), K(i, j)$, and $u(i, j)$ are treated as spatially periodic functions. For example, when the model fault is divided into $1024 \times 1024$ cells, $K(i+1024$, $j+1024)=K(i, j)$.

We assume the rate- and state-dependent friction law (Dieterich 1979; Ruina 1983)

$$
\tau=\tau_{*}+A \ln \left(\frac{V}{V_{*}}\right)+B \ln \left(\frac{\theta}{L / V_{*}}\right)
$$

with

$$
A=a \sigma, \quad B=b \sigma,
$$

where $\sigma$ is the effective normal stress, $a$ and $b$ are friction parameters, $L$ is the characteristic slip, $\theta$ is a state variable, $V_{*}$ is an arbitrarily chosen reference velocity, and $\tau_{*}$ is the steady-state shear stress at $V=V_{*}$. In this paper, we use the Nagata law (Nagata et al. 2012) for evolution, which was developed by revising the aging law, and is given as

$$
\frac{\mathrm{d} \theta}{\mathrm{d} t}=1-\frac{V \theta}{L}-\frac{c \theta}{B} \frac{\mathrm{d} \tau}{\mathrm{d} t}
$$

where $c$ is the coefficient of the stress-weakening effect and is approximately 2 based on laboratory experiment by Nagata et al. (2012). Nagata et al. (2012) interpreted such effect is caused by elastic deformation when the shear stress increases that results in the partial breakage of junction bonds of asperities. The initial conditions assume steady-state values for a uniform sliding velocity.

We first simulate the afterslip assuming a model fault with a constant positive value of $A-B$ without a patch having a negative value of $A-B$. Fukuda et al. (2013) estimated the afterslip from the inversion analysis of GPS data for the period from the occurrence time of the 2011 Tohoku-oki earthquake (March 11, 2011) to October 17, 2011.

We simulate the afterslip by replacing $V_{\mathrm{pl}} t$ in Eq. (1) with $V_{\mathrm{pl}} t+s(t)$, where

$$
s(t)=D \ln \left(t / T_{0}+1\right) H(t)
$$

Here, $H(t)$ is the Heaviside-step function, $D$ and $T_{0}$ are constants, and the $M 9$ event is assumed to occur at $t=0$. The square fault is divided into $1024 \times 1024$ cells with dimensions of $\Delta x=\Delta y=0.025 \mathrm{~km}$. In this model, $V_{\mathrm{pl}}$ $t+s(t)$ may correspond to the displacement of the virtual loading point for the model fault. The parameters $D$ and $T_{0}$ that fit the afterslip at the location of the Kamaishi repeater estimated by Fukuda et al. (2013) are determined by the trial and error. Figure 4a shows the afterslip including the steady slip $V_{\mathrm{pl}} t$ estimated by Fukuda et al. (2013), the simulated afterslip, and the displacement of the virtual loading point. The assumed values are $A-B=0.222 \mathrm{MPa}, L=0.0049 \mathrm{~m}, T_{0}=0.012$ year, and $D /\left(V_{\mathrm{pl}} T_{0}\right)=630$, which implies $\mathrm{d} s / \mathrm{d} t=630 V_{P l}$ at $t=0$. These values differ from those assumed in Yoshida et al. (2015). Since our goal is to forecast the events that occurred after the analysis period of afterslip inversion by Fukuda et al. (2013), we obtained a good fit to the last half (from 0.3 to 0.6 year) of the observed afterslip as shown in Fig. 4b, whereas an overall fit was obtained by Yoshida et al. (2015). Fukuda et al. (2013) pointed out that the best fit during the first 15 days of the afterslip does not reproduce the subsequent slip when they assumed a persistence value of $A-B$.

Next, we assume a conditionally stable circular patch with a radius of $5.5 \mathrm{~km}$ containing a small unstable circular patch with a radius of $0.8 \mathrm{~km}$, as denoted by red and green circles in Fig. 5a. This model corresponds to the Case 3 model in Yoshida et al. (2015). The spatial distributions of $A-B$ and $L$ are schematically shown in Fig. 5; $A-B$ has a constant negative value $(A-B)_{1}$ in the large patch for $r<5.5 \mathrm{~km}$ (except inside the small patch) and a constant positive value $(A-B)_{2}$ in the surrounding region for $r>6.05 \mathrm{~km}$, where $r$ is the distance from the center of the circular patch. The value of $A-B$ decreases linearly with $r$ from $(A-B)_{1}$ to $(A-B)_{2}$ for $5.5 \mathrm{~km}<r<6.05 \mathrm{~km}$. $A$ and $c$ are assumed to be uniform over the fault, whereas $B$ and $L$ are non-uniformly distributed. $L_{1}$ inside the large patch and $L_{2}$ outside the large patch are assumed to be equal. The small patch has values of $(A-B)_{3}$ and $L_{3}$. We perform simulations for two groups: group 1 with $L_{1}=L_{2}=0.0046 \mathrm{~m}$ and $L_{3}=0.0021 \mathrm{~m}$, and group 2 with $L_{1}=L_{2}=0.0049 \mathrm{~m}$ and $L_{3}=0.0024 \mathrm{~m}$, assuming various values of $(A-B)_{3}$ in a 


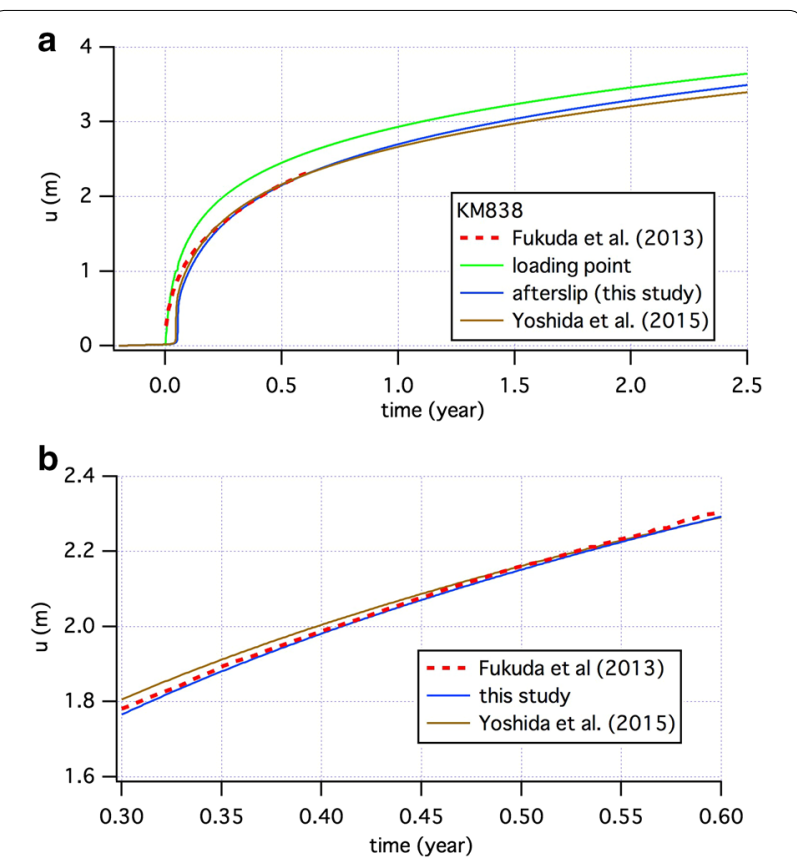

Fig. 4 a Afterslip estimated by Fukuda et al. (2013), displacement of the virtual loading point in the simulation, and simulated afterslip for the homogeneous model fault with $A=3.3 \mathrm{MPa}, A-B=0.222 \mathrm{MPa}$, $L=0.0049 \mathrm{~m}$, and $c=2.0$ for the Nagata law. For comparison, afterslip assumed in Yoshida et al. (2015) is plotted. b Comparison between the afterslip of this paper and that of Yoshida et al. (2015) from 0.3 to 0.6 year range of -0.73 to $-0.65 \mathrm{MPa}$. The square fault is divided into $1,048,576(=1024 \times 1024)$ cells with dimensions of $\Delta x=\Delta y=0.025 \mathrm{~km}$.

An example of a group 2 simulation with $(A-B)_{3}=-0.666 \mathrm{MPa}$ is discussed here. Figure 6a shows a magnitude-time plot for pre- and post- $M 9$ time windows with the event numbers labeled. To be comparable with the observation, the $M 9$ event was set to occur at $56 \%$ of the recurrence cycle since the latest pre-M9 repeating event (A5 in Fig. 6). In Fig. 6, $t=0$ is taken as the occurrence time of the $M 9$ event. The moment magnitude was calculated from the seismic moment (Hanks and Kanamori 1979), assuming that the seismic slip exceeds or is equal to $0.01 \mathrm{~m} / \mathrm{s}$ (Chen and Lapusta 2009). Larger $M_{\mathrm{w}}$ is estimated for smaller threshold as Yoshida et al. (2015) reported that $M_{\mathrm{w}} 4.78$ event under assumption of $0.01 \mathrm{~m} / \mathrm{s}$ changed to $M_{\mathrm{w}} 4.69$ for $0.02 \mathrm{~m} / \mathrm{s}$ and to $M_{\mathrm{w}} 4.88$ for $0.005 \mathrm{~m} / \mathrm{s}$. Before the $M 9$ event, M5-class events occurred repeatedly in the small patch. When the afterslip of the $M 9$ event occurred, a large event (B1, M6.28 in Fig. 6b) occurred over the entire area of the large patch and was followed by small events (B2-11 in Fig. 6) that ruptured the small patch. The recurrence interval was much shorter than pre- $M 9$ period because of the fast loading rate. The interval gradually increased as the rate of the afterslip decreased. The magnitudes of the events after B1 are smaller than pre-M9 level. This

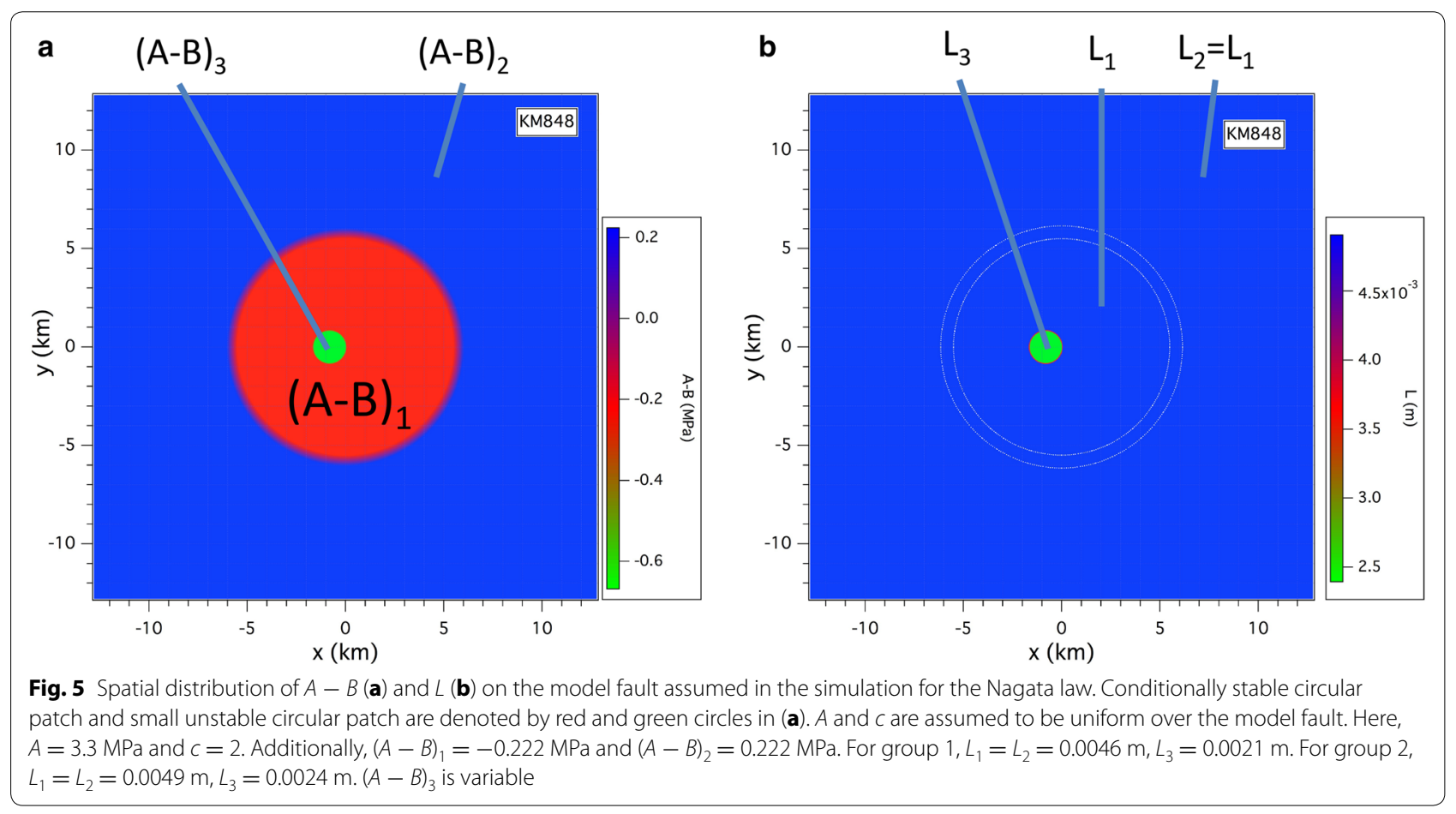



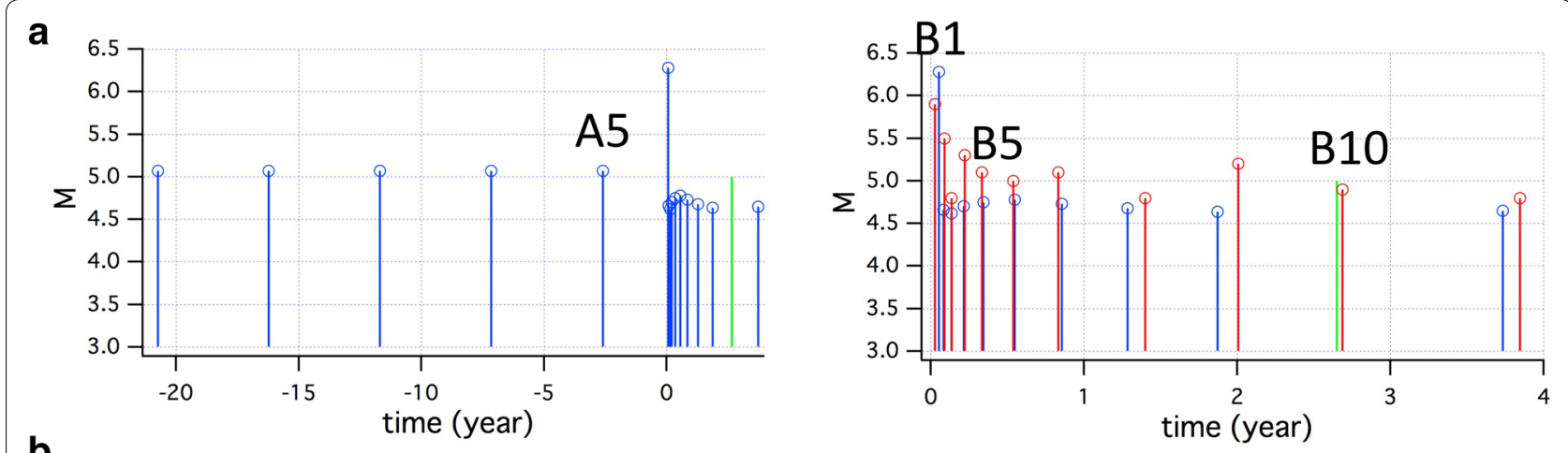

b
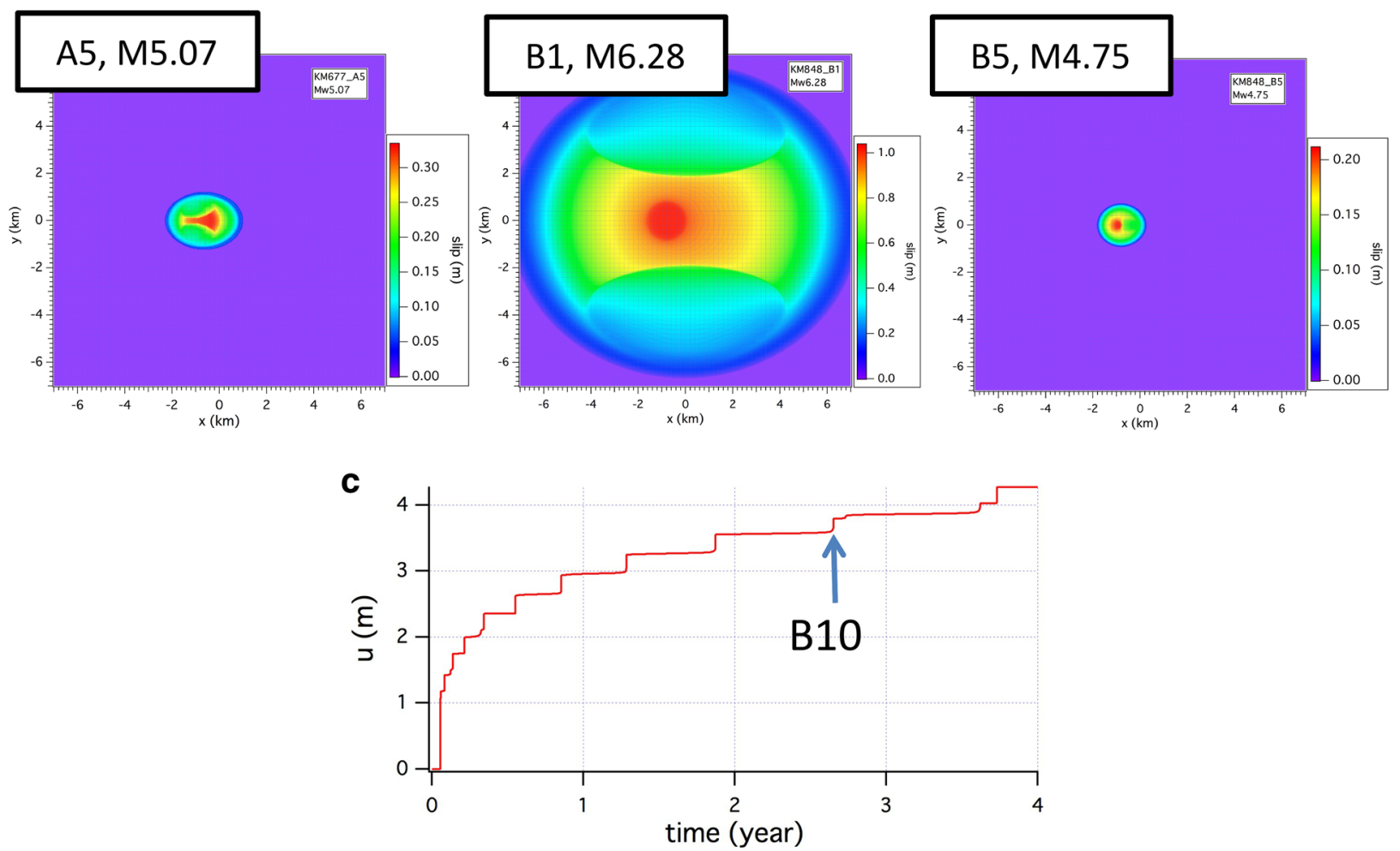

Fig. 6 Example of the simulation using a modeled sequence in group 2 assuming $(A-B)_{3}=0.666 \mathrm{MPa}$. a Magnitude-time plot. Red circles denote the magnitudes observed by Uchida et al. (2014), blue circles show the simulated magnitudes, and green lines show slow event in the simulation. $\mathbf{b}$ Spatial distributions of the seismic slip of events A5 (M5.07), B1 (M6.28), and B5 (M4.73). c Slip histories after the M9 event at the center of the small patch. B10 is a slow slip event with a maximum slip velocity of less than $0.01 \mathrm{~m} / \mathrm{s}$, and thus, its magnitude is undefined

is likely due to weaker recovery of the strength for typical asperities with shorter recurrence time. Although the occurrence times are well reproduced in the simulation, the magnitude of repeating events, however, is generally smaller than the observation shown by red lines and circles in Fig. 6a.

Figure $6 \mathrm{c}$ shows the post- $M 9$ history of the slip at the center of the small patch. At $t=2.65$ years, a slow slip event occurred with a maximum slip rate less than $0.01 \mathrm{~m} / \mathrm{s}$. When other values of $(A-B)_{3}$ were assumed, the corresponding event (B10) was a seismic event in many cases. If a threshold of $0.001 \mathrm{~m} / \mathrm{s}$ is assumed, the estimated magnitude of this event would be M4.08. As the threshold is taken to be $0.01 \mathrm{~m} / \mathrm{s}$ in this paper, this event is treated as an event with an undefined magnitude. In Fig. 6a, the green line shows the occurrence time of this event. If we include this event of undefined magnitude, 11 seismic events were simulated to occur between the $M 9$ event and the present time, comparable to the observation. In the next section, the occurrence time of this event of undefined magnitude (B10) is used as a data point to obtain a forecast of occurrence time; however, 
this event is not used as a data point when forecasting the magnitude.

\section{Forecast experiment}

We performed numerical simulations assuming various values of $(A-B)_{3}$ in the small patch for the two groups. As stated above, group 1 has $L_{1}=L_{2}=0.0046$ and $L_{3}=0.0021 \mathrm{~m}$, and group 2 has $L_{1}=L_{2}=0.0049 \mathrm{~m}$, $L_{3}=0.0024 \mathrm{~m}$. The rupture of the small patch is mainly controlled by the frictional parameters of the small patch, $(A-B)_{3}$ and $L_{3}$. We assumed various values of $(A-B)_{3}$. Although it was desirable to assume a number of values for $L_{3}$, we assumed two values because of computation cost. Figure 7 shows the modeled sequences, which are used as data for forecast experiments. To forecast the occurrence time and the magnitude of the Ith event, we average the individual forecasts of the Ith event over some selected sequences that can reproduce the observed sequence up to the $(I-1)$ th events. This procedure yields an ensemble forecast. The idea of an ensemble average is based on weather computation forecasting procedures (e.g., Barker 1991; Yamaguchi et al. 2009).

Immediately after the $M 9$ event, the simulated event ruptured the large patch, resulting in an M6-class event in every modeled sequence, while other events ruptured only the small patch, resulting in a series of M5-class events. In Fig. 7, the triangles denote slow slip events in which the maximum slip velocity is less than $0.01 \mathrm{~m} / \mathrm{s}$, and the magnitude is undefined. When two slow slip events occurred at a short interval in some sequences, we calculated seismic moments for velocities larger than $10^{-3}$ or $10^{-4} \mathrm{~m} / \mathrm{s}$, and we selected the event with the larger seismic moment as a forecast data point. The smaller events denoted by open triangles were not used as data points in our forecast experiments. In many modeled sequences of group 1 , an event occurred the day after the occurrence of the first M6-class event (B1); this event is denoted by a green circle. As such an event was not reported in the observation, it was excluded from the forecast data.

Figure 7 shows that the feature of the event sequence changes continuously with the values of $(A-B)_{3}$. However, discontinuous changes were obtained in some places, for example, at $(A-B)_{3}=-0.68 \mathrm{MPa}$ in group 1 . A slow slip event occurred at $(A-B)_{3}=-0.682 \mathrm{MPa}$ in the sequence near the discontinuous change. Such behavior of discontinuity and slow slip near the discontinuity can be seen around $(A-B)_{3}=-0.69 \mathrm{MPa}$ in group 2 . For $(A-B)_{3}=-0.66 \mathrm{MPa}$ in group 2, after two seismic events and a subsequent slow slip event occurred,

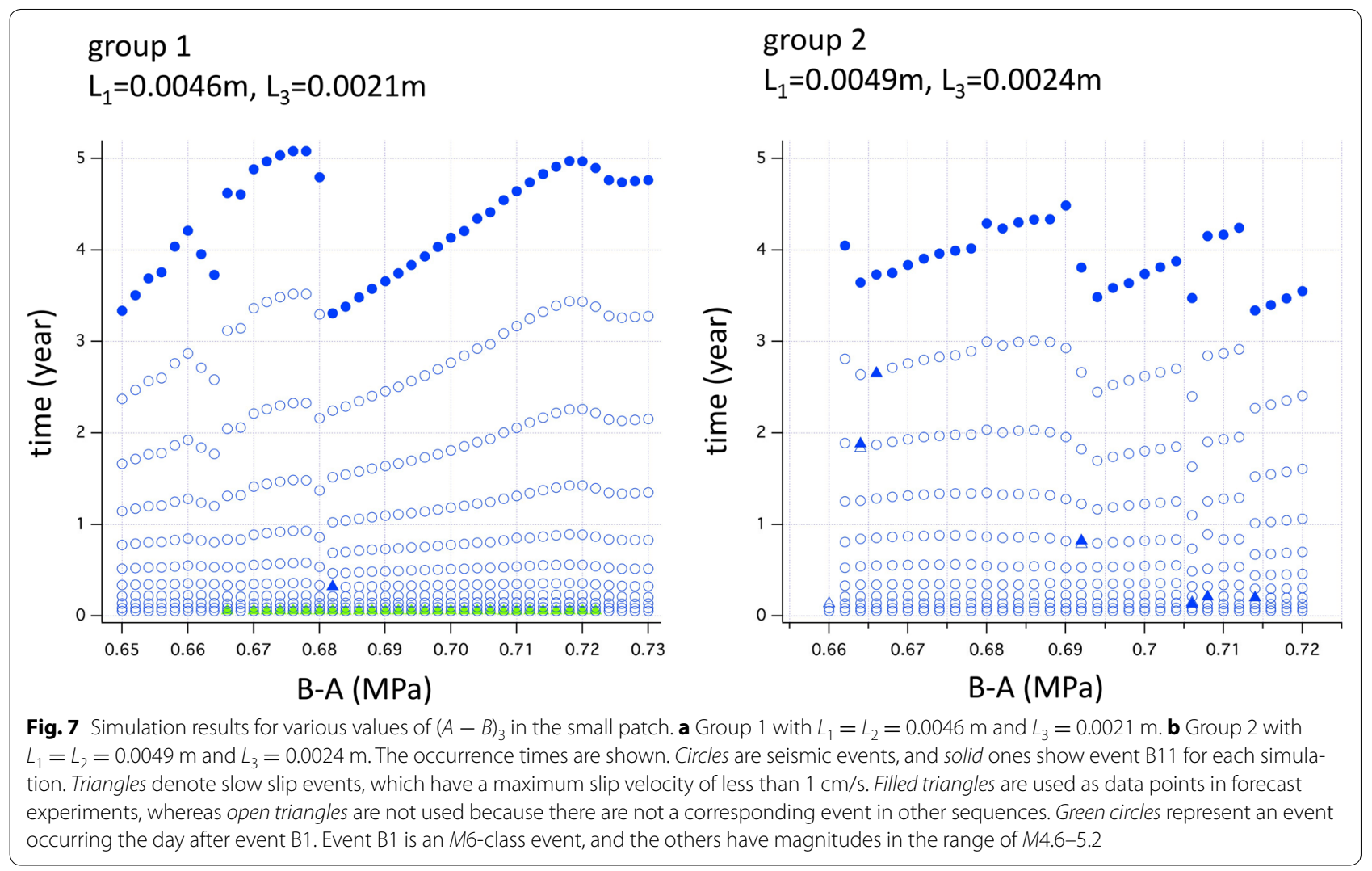


slow sliding continued until the next seismic event at $t=8.96$ years, which is beyond the range shown in Fig. 7 .

To forecast the Ith event, we selected modeled sequences that accurately reflect the observed occurrence times of all the event that occurred before the target event. For the $j$ th modeled sequence, we calculated

$$
\sigma_{I-1}^{j}=\sqrt{\sum_{i=1}^{I-1}\left(T_{i}^{j}-T_{i}^{\mathrm{obs}}\right)^{2} /(I-1)}
$$

where $T_{\mathrm{i}}^{j}$ is individual forecast of the occurrence time of the $i$ th event in the $j$ th sequence, and $T_{i}^{\text {obs }}$ is the observed occurrence time of the $i$ th event. We sorted the modeled sequences in ascending order of $\sigma_{I-1}^{j}$ to select the top $J$ sequences from the first $J$ ranks; $J$ was set to $5,10,15$, or 20 . The ensemble forecast of the occurrence time of the Ith event is defined as the average $T_{\mathrm{I}}^{\mathrm{av}}$ over the selected $J$ sequences:

$$
T_{I}^{\mathrm{av}}=\frac{1}{J} \sum_{j=1}^{J} T_{I}^{j}
$$

We also obtained $T_{\mathrm{I}}^{\mathrm{wt}}$ that minimizes the weighted residuals, as

$$
\sum_{j=1}^{J}\left\{\left(T_{I}^{j}-T_{I}^{\mathrm{wt}}\right) / \sigma_{I-1}^{j}\right\}^{2}=\min
$$

We measure the forecast spreads in a root square sense, as

$$
\varepsilon_{I}=\sqrt{\sum_{j=1}^{J}\left(T_{I}^{j}-T_{I}^{\mathrm{av}}\right)^{2} / J}
$$

or

$$
\varepsilon_{I}^{\prime}=\sqrt{\sum_{j=1}^{J}\left(T_{I}^{j}-T_{I}^{\mathrm{wt}}\right)^{2} / J}
$$

An ensemble forecast of the magnitude is given by the average over the same selected $J$ sequences. If the $I$ th event of a sequence has an undefined magnitude, the average of $(J-1)$ events is used, excluding the event of undefined magnitude. We measured the forecast variability, or spread, of the magnitude as

$$
\eta_{I}=\sqrt{\sum_{j=1}^{J}\left(\mu_{I-1}^{j}\right)^{2} / J}
$$

where

$$
\mu_{I-1}^{j}=\sqrt{\sum_{i=1}^{I-1}\left(M_{i}^{j}-M_{i}^{\mathrm{obs}}\right)^{2} /(I-1)}
$$

As individual forecast of the magnitude does not differ from each other for different modeled sequences, if the forecast spread is obtained in the same manner as the occurrence time, this would yield an underestimation for the forecast spread. When a modeled sequence includes an event of undefined magnitude in the first $(I-1)$ events, Eq. (12) is calculated by excluding this event and replacing $(I-1)$ with $(I-2)$.

\section{Results}

On the basis of the calculation using Eqs. (6)-(12), we demonstrate the forecasting of events B7-B11. Figure 8 shows the modeled sequences selected from group 1 and group 2 by evaluating $\sigma_{6}^{j}$ using Eq. (6) for the forecasting of event B7. Blue arrow in Fig. 8 denotes the analysis period of afterslip inversion by Fukuda et al. (2013). The target events of forecast occur after this period. The sequences outlined in red show the top 5 sequences that can best reproduce the occurrence times of events B1B6, and those outlined in yellow, green, and blue show modeled sequences of ranks 6-10, 11-15, and 16-20, respectively. We obtain forecasts using the method described in the previous section with ensembles of the top $5,10,15$, and 20 sequences. The individual forecasts of the occurrence time of event B7 obtained by each of the top 20 sequences were in good agreement with the observed occurrence times, as shown in Fig. 8.

The results of the ensemble forecasts using group 1 and group 2 are summarized in Table 1. A good forecast is obtained for event B7, as the forecast errors $\left|T^{\mathrm{av}}-T^{\mathrm{obs}}\right|$ and $\left|T^{\mathrm{wt}}-T^{\mathrm{obs}}\right|$ are reasonably small for every ensemble. Additionally, the errors are smaller than the ensemble forecast spreads. The forecast errors decreased as the number of the ensemble sequences $U$ in Eq. (7)] increased, suggesting that the ones that accurately reflect the observed occurrence times of event B1-B6 do not forecast event B7 better than the lower rank. The ensemble forecasts of the magnitude of event B7 are approximately 4.8 for all the ensembles, and the errors are smaller than the forecast spreads.

Figures 9, 10, 11 and 12 show the selected sequences used to forecast event B8-B11. When the target event is B8, we calculate $\sigma_{7}^{j}$ using Eq. (6) with occurrence times of B1-B7. Table 1 shows that the accuracy of forecasting the occurrence time of event B8 is not good and that the errors are larger than the forecast spreads. The forecast obtained using the top 5 sequences provides the smallest error among the ensembles. This means that the modeled sequences that accurately reflect the occurrence times of the first seven events (B1-B7) can predict the next event better. For this reason, $T^{\mathrm{wt}}$ provides a better forecast than $T^{\text {av }}$. In Fig. 9, the individual forecasts of B8's occurrence time using the top 5 modeled sequences are in better 


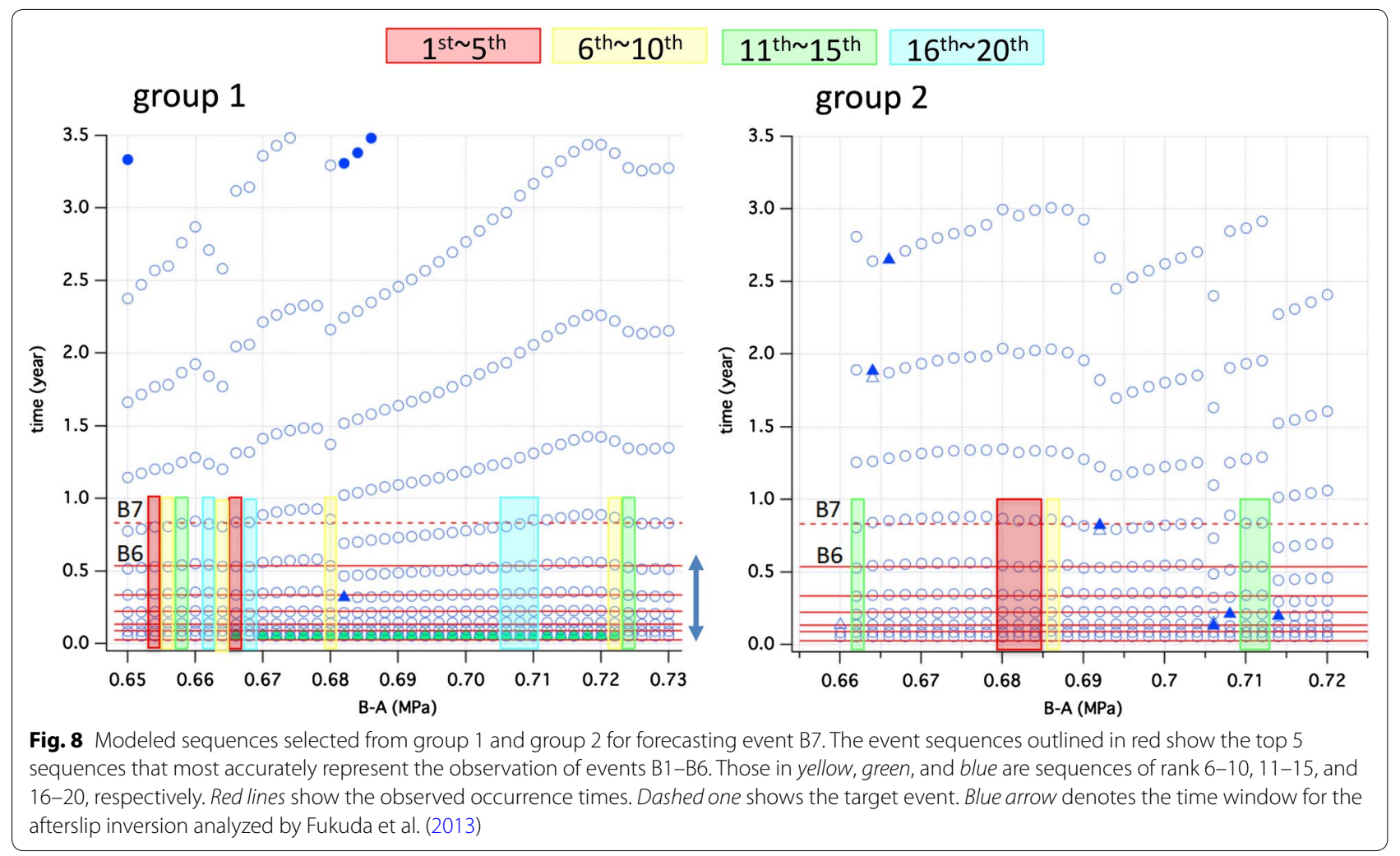

Table 1 Forecast results using groups 1 and 2

\begin{tabular}{|c|c|c|c|c|c|c|c|c|c|}
\hline Event & $\begin{array}{l}\mathrm{T}^{\text {obs }} \\
\text { (year) }\end{array}$ & $\begin{array}{l}\text { Num. } \\
\text { of sequences }\end{array}$ & $\begin{array}{l}\mathrm{T}^{\mathrm{av}}-\mathrm{T}^{\mathrm{obs}} \\
\text { (day) }\end{array}$ & $\begin{array}{l}\text { Forecast } \\
\text { spread (day) }\end{array}$ & $\begin{array}{l}T^{w t}-T^{\text {obs }} \\
\text { (day) }\end{array}$ & $\begin{array}{l}\text { Forecast } \\
\text { spread (day) }\end{array}$ & $M^{\text {obs }}$ & $M^{\text {av }}$ & $\begin{array}{l}\text { Forecast } \\
\text { spread }\end{array}$ \\
\hline \multirow[t]{4}{*}{ B7 } & 0.831445 & 5 & 4.5 & 8.2 & 4.6 & 8.2 & 5.1 & 4.78 & 0.52 \\
\hline & & 10 & 3.8 & 9.3 & 3.9 & 9.3 & & 4.79 & 0.49 \\
\hline & & 15 & 3.0 & 7.8 & 3.2 & 7.8 & & 4.79 & 0.47 \\
\hline & & 20 & 2.1 & 7.2 & 2.3 & 7.5 & & 4.79 & 0.47 \\
\hline \multirow[t]{4}{*}{ B8 } & 1.399565 & 5 & -37.9 & 12.0 & -37.8 & 12.0 & 4.8 & 4.85 & 0.42 \\
\hline & & 10 & -43.4 & 13.2 & -42.7 & 13.2 & & 4.81 & 0.43 \\
\hline & & 15 & -41.5 & 14.2 & -41.3 & 14.2 & & 4.83 & 0.44 \\
\hline & & 20 & -43.0 & 15.0 & -42.6 & 15.0 & & 4.82 & 0.44 \\
\hline \multirow[t]{4}{*}{ B9 } & 2.005906 & 5 & 65.6 & 10.8 & 66.1 & 10.9 & 5.2 & 5.13 & 0.39 \\
\hline & & 10 & 55.9 & 19.2 & 58.5 & 19.4 & & 5.08 & 0.40 \\
\hline & & 15 & 53.9 & 27.1 & 56.4 & 27.3 & & 5.06 & 0.40 \\
\hline & & 20 & 41.3 & 32.7 & 48.1 & 33.4 & & 5.00 & 0.40 \\
\hline \multirow[t]{4}{*}{ B10 } & 2.685848 & 5 & 103.2 & 15.5 & 104.6 & 16.0 & 4.9 & 4.80 & 0.42 \\
\hline & & 10 & 106.7 & 35.7 & 105.6 & 35.7 & & 4.84 & 0.42 \\
\hline & & 15 & 102.7 & 44.7 & 103.4 & 44.7 & & 4.89 & 0.41 \\
\hline & & 20 & 105.6 & 55.7 & 105.5 & 55.7 & & 4.88 & 0.41 \\
\hline \multirow[t]{4}{*}{ B11 } & 3.84531 & 5 & -3.5 & 32.2 & -3.6 & 32.2 & 4.8 & 4.71 & 0.42 \\
\hline & & 10 & 10.7 & 46.1 & 5.7 & 46.4 & & 4.74 & 0.41 \\
\hline & & 15 & 30.6 & 56.1 & 20.6 & 57.0 & & 4.79 & 0.41 \\
\hline & & 20 & 44.9 & 74.5 & 30.6 & 75.8 & & 4.81 & 0.40 \\
\hline
\end{tabular}



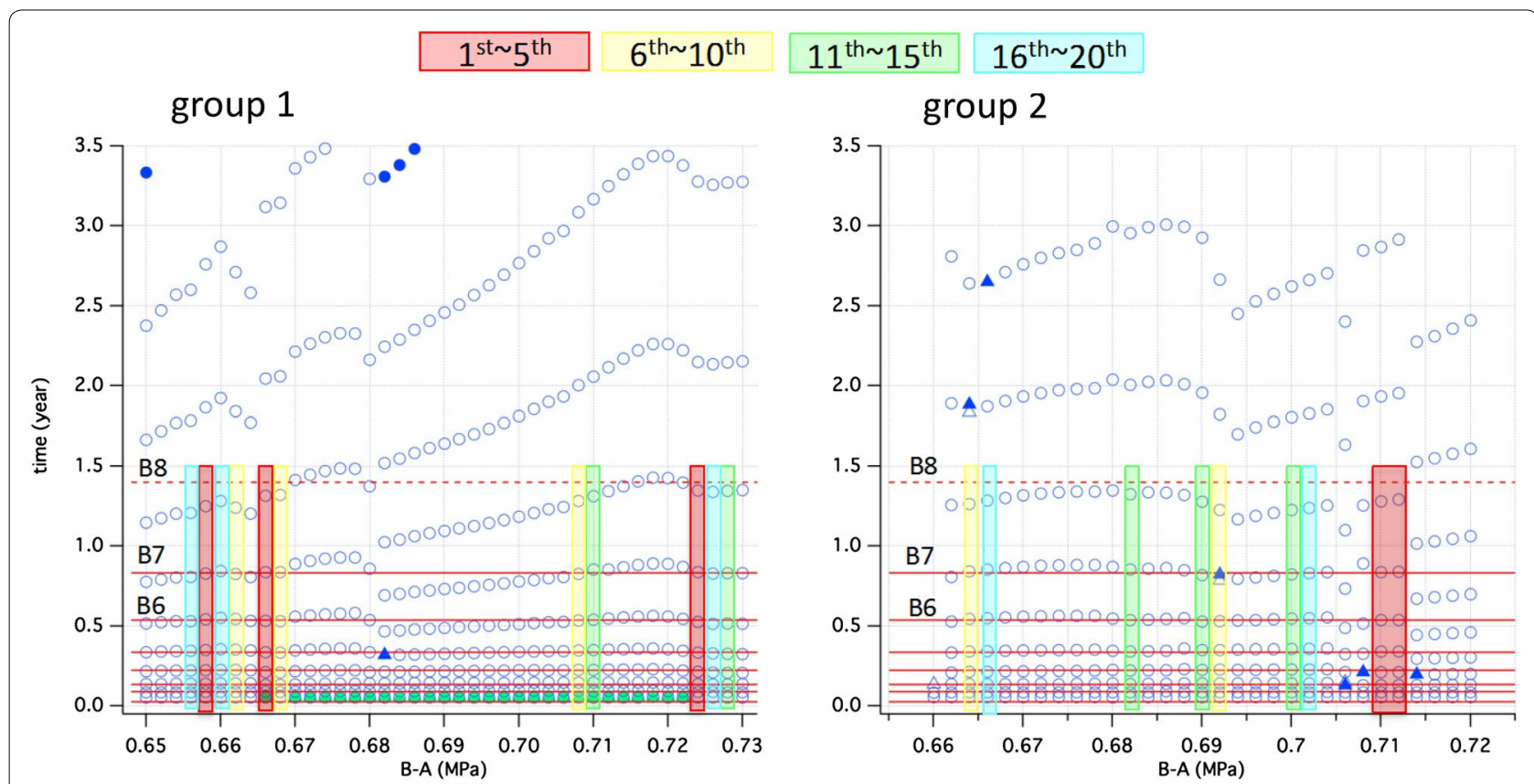

Fig. 9 Same as Fig. 8 for forecasting event $B 8$

agreement with the observation than lower-rank sequen ces.

Forecasts of the occurrence time of event B9 are not accurate. The errors decreased as the number of modeled sequences increased. Figure 10 shows that the occurrence times of event B9 forecasted using modeled sequences of rank 16-20 are close to the observed occurrence time, although the forecasts obtained using the top 5 sequences, which belong in group 1, were far from the observation.
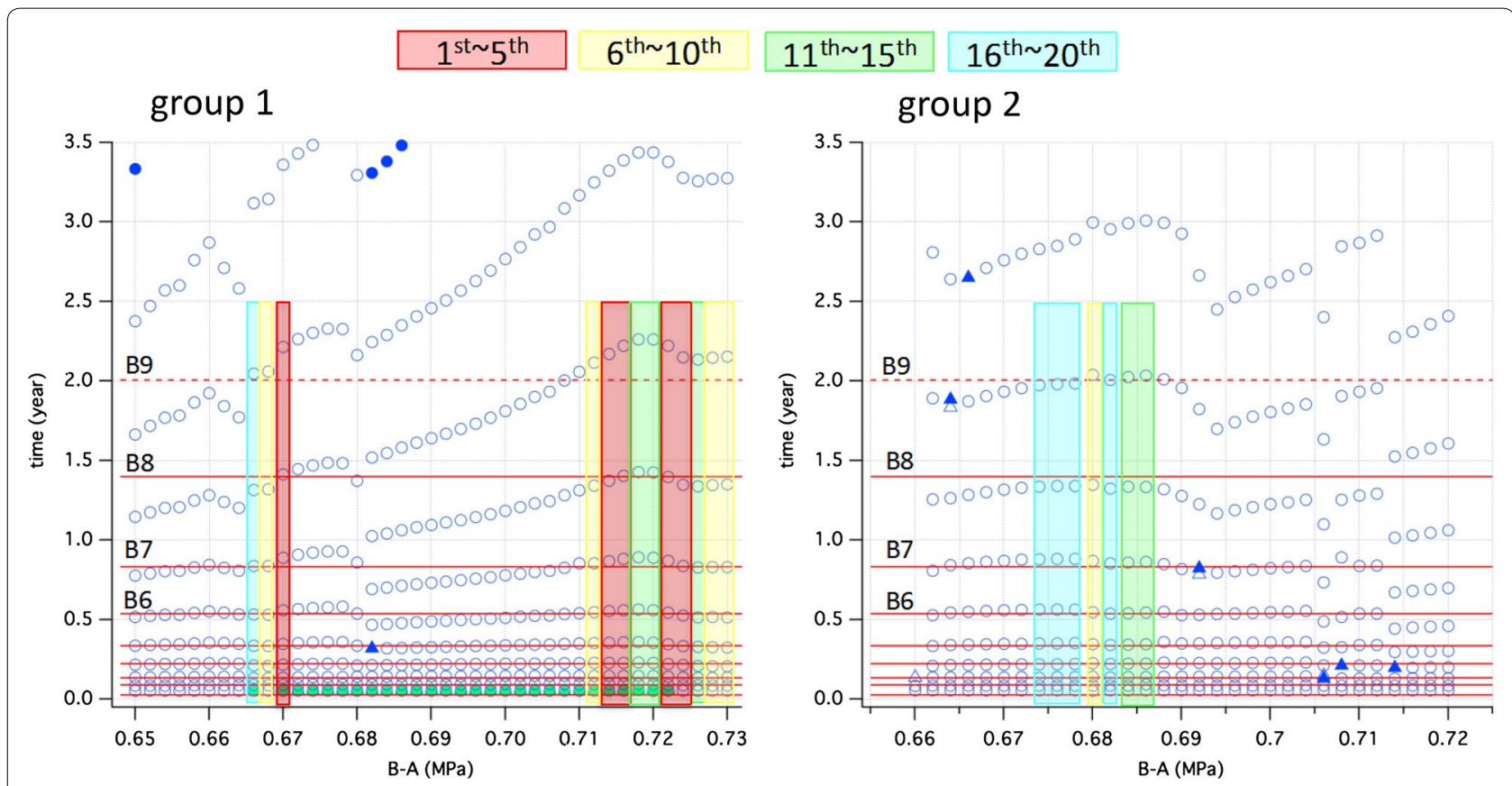

Fig. 10 Same as Fig. 8 for forecasting event B9 
The forecasts of B10's occurrence time are incorrect. Errors larger than 100 days are mainly caused by the errors from the selected sequences from group 1 , as shown in Fig. 11. The individual forecasts obtained using group 2 sequences are much better than those using group 1 sequences.

The forecasts of the occurrence time of event B11 are found to be relatively good (Fig. 12). The errors are smaller than the forecast spreads. Considering that event B11 occurred 3.8 years after the $M 9$ event, errors less than 45 days can be regarded as small. The errors of the forecasted occurrence time obtained using the top 5 sequences are approximately 4 days.

The forecasted magnitude of B7-B11 does not differ significantly from event to event. The magnitude of event B9 is predicted to be approximately $M 5-M 5.1$, which is larger than the other events. This is likely due to that many of the selected sequences have large $|A-B|$ values and belong to group 1 with smaller $L$ value than in group 2 , leading to large seismic events. The observed magnitudes of event B7-B11 does not differ significantly. The forecast errors are less than the forecast spread for these five events.

The number of the selected top 20 sequences outlined in Figs. 7, 8, 9, 10, 11 and 12 belonging to group 2 increases for later event. Seven sequences are selected from group 2 to forecast event B9, whereas 17 are selected to forecast event B11. This means that the sequences in group 2 reproduce the event sequence over a long period better than those in group 1. As mentioned in section "Numerical simulation model," many modeled sequences in group 1 yield an event that occurs the day after the first M6-class event. Given that this simulated event corresponds to no one in the observed sequence, these modeled sequences are considered to be unable to accurately reproduce the observed sequence.

Therefore, we next perform a forecast selecting the modeled sequences (Table 2) from group 2, leading to the results given in Table 3. In comparison with the forecasts obtained by group 1 and group 2, forecasts of events B9 and $\mathrm{B} 10$ are improved, and those for the others differ little. To assess the average error over the five events (B7B11), we calculate

$$
\begin{aligned}
\sigma^{\mathrm{av}} & =\sqrt{\sum_{I=7}^{11}\left(T_{I}^{\mathrm{av}}-T_{I}^{\mathrm{obs}}\right)^{2} / 5} \text { and } \\
\sigma^{\mathrm{wt}} & =\sqrt{\sum_{I=7}^{11}\left(T_{I}^{\mathrm{wt}}-T_{I}^{\mathrm{obs}}\right)^{2} / 5}
\end{aligned}
$$

for each ensemble consisting of $5,10,15$, or 20 sequences. Table 4 shows that the agreements between the observations and the forecasts obtained using only group 2 are improved comparing with the one using both groups for all ensembles. The average error for the ensemble consisting of the top 15 sequences of group 2 reaches a minimum value of 40.1 days, although the difference among result using group 2 is not significant.

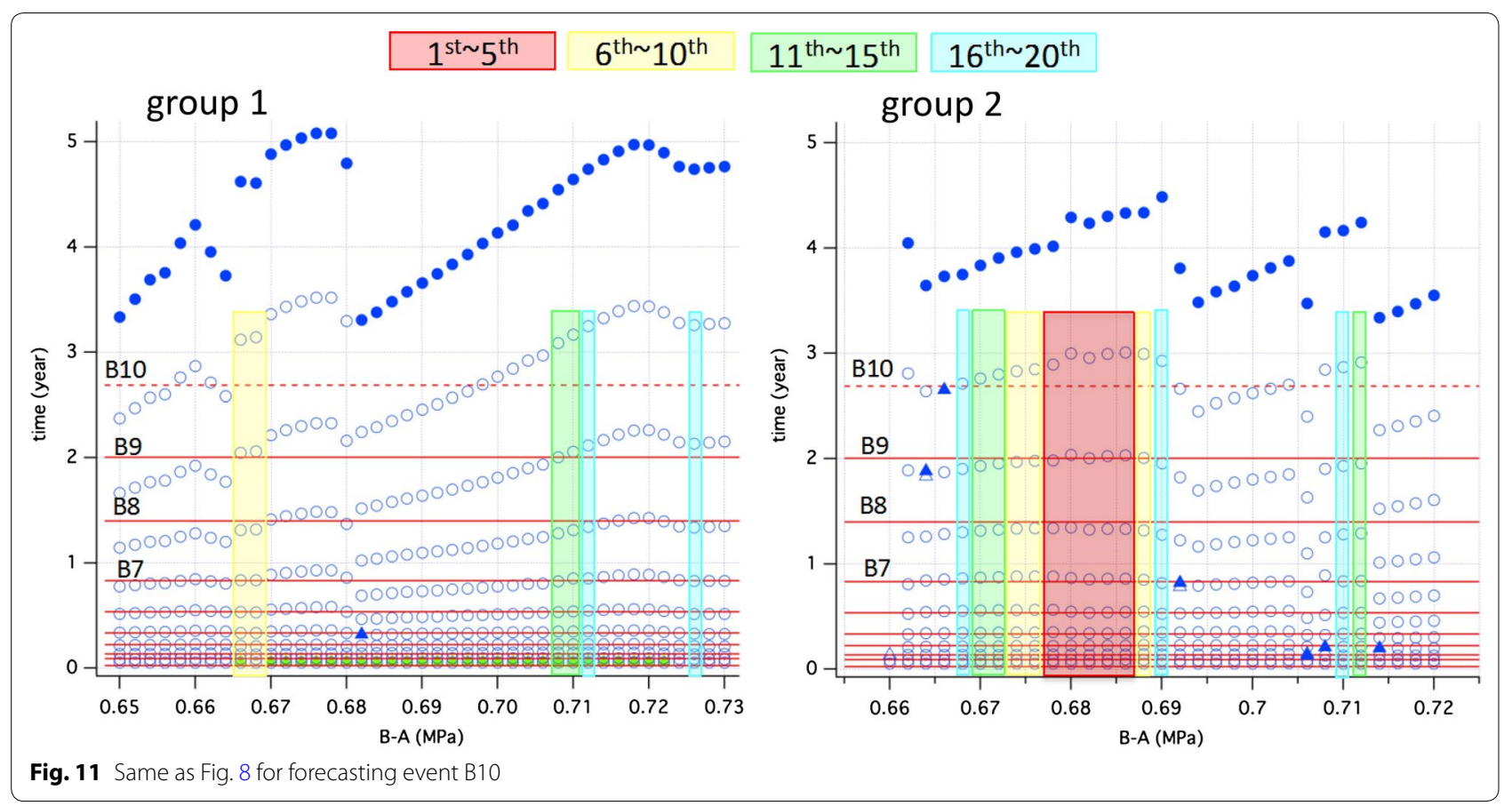




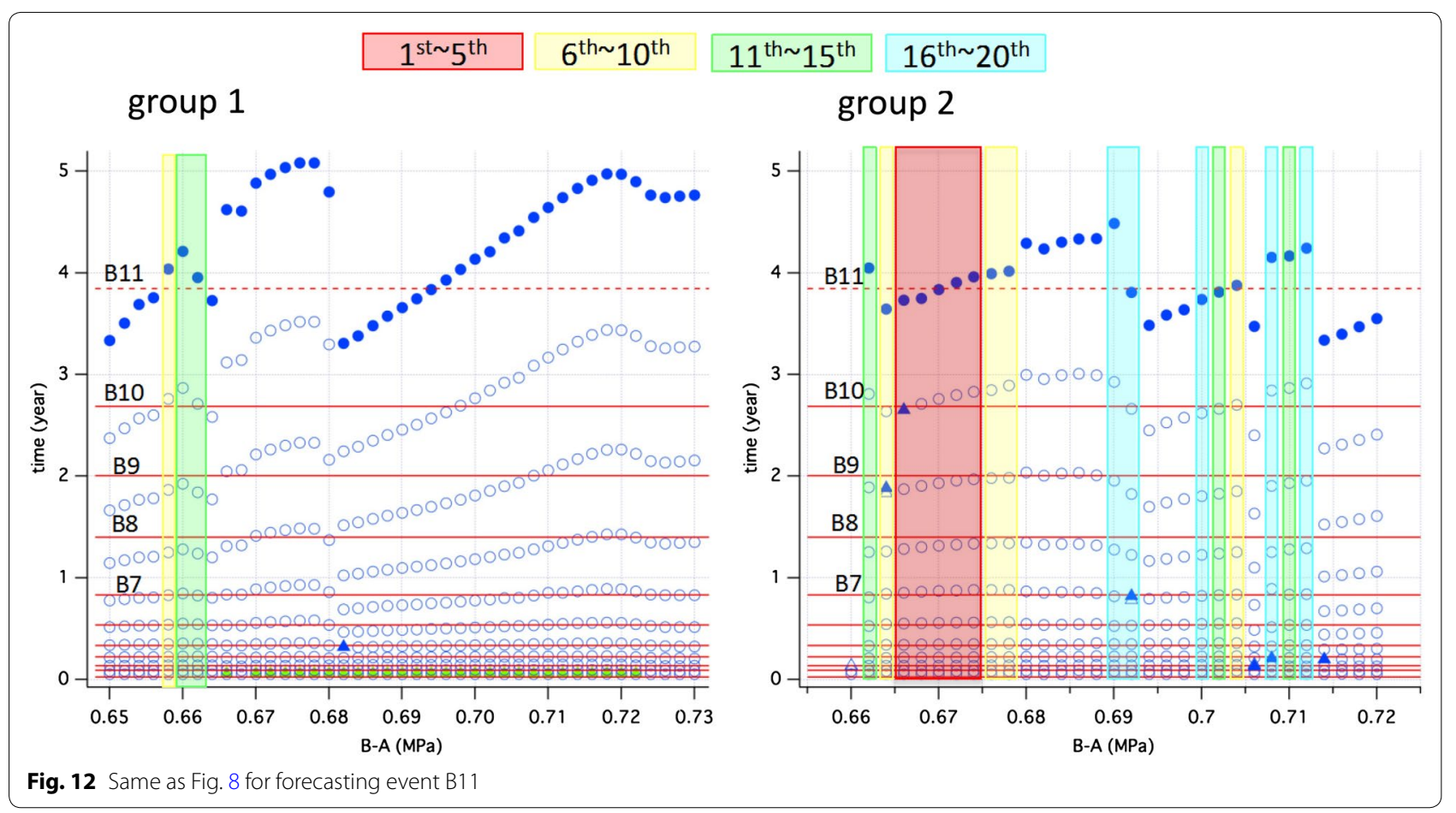

Table $2(B-A)_{3}$ of modeled sequences selected from group 2 for forecasting B7-B11

\begin{tabular}{llllll}
\hline Rank & B7 & B8 & B9 & B10 & B11 \\
\hline 1 & 0.662 & 0.662 & 0.682 & 0.662 & 0.662 \\
2 & 0.664 & 0.664 & 0.684 & 0.664 & 0.664 \\
3 & 0.666 & 0.666 & 0.666 & 0.666 & 0.666 \\
4 & 0.668 & 0.668 & 0.668 & 0.668 & 0.668 \\
5 & 0.670 & 0.670 & 0.670 & 0.670 & 0.670 \\
6 & 0.672 & 0.680 & 0.672 & 0.672 & 0.672 \\
7 & 0.680 & 0.682 & 0.674 & 0.674 & 0.674 \\
8 & 0.682 & 0.684 & 0.676 & 0.676 & 0.676 \\
9 & 0.684 & 0.686 & 0.678 & 0.678 & 0.678 \\
10 & 0.686 & 0.688 & 0.680 & 0.680 & 0.680 \\
11 & 0.690 & 0.690 & 0.682 & 0.682 & 0.682 \\
12 & 0.692 & 0.692 & 0.684 & 0.684 & 0.684 \\
13 & 0.694 & 0.694 & 0.686 & 0.686 & 0.690 \\
14 & 0.696 & 0.696 & 0.688 & 0.688 & 0.692 \\
15 & 0.698 & 0.698 & 0.690 & 0.690 & 0.700 \\
16 & 0.700 & 0.700 & 0.702 & 0.702 & 0.702 \\
17 & 0.702 & 0.702 & 0.704 & 0.704 & 0.704 \\
18 & 0.708 & 0.704 & 0.708 & 0.708 & 0.708 \\
19 & 0.710 & 0.710 & 0.710 & 0.710 & 0.710 \\
20 & 0.712 & 0.712 & 0.712 & 0.712 & 0.712 \\
\hline
\end{tabular}

Modeled sequences that can accurately reproduce past events do not always forecast the next event better. Forecast uncertainties are generated from the uncertainties of many factors, such as friction parameters, initial conditions, and the model itself. The procedure of obtaining the ensemble average seems useful for providing reasonable forecasts.

\section{Discussion and summary}

This paper performed earthquake forecast experiments by using numerical simulations. However, the forecasting method described here remains to be improved. The idea of using the ensemble average was adapted from weather forecasts (e.g., Barker 1991; Yamaguchi et al. 2009); however, many conditions in this paper have distinct disadvantages compared with the weather forecast. Major uncertainties in the weather simulation are generated by uncertainties in the initial conditions, which are obtained from the observation. The ensemble average is provided over the several sequences, assuming non-perturbed and perturbed initial conditions. The initial conditions can be replaced with new conditions as time progresses.

Unlike in weather forecasting, uncertainties in earthquake simulations are caused by uncertainties in many factors. The values of physical parameters and the initial conditions are unknown. In this paper, some of the unknown parameters were varied in limited ranges. In principle, if more parameters were varied in wider ranges, this problem could be solved. In practice, such an approach is difficult unless a much faster computation system is developed. Initial conditions cannot 
Table 3 Forecast results using group 2

\begin{tabular}{|c|c|c|c|c|c|c|c|c|c|}
\hline Event & $\mathrm{T}^{\text {obs }}$ (year) & $\begin{array}{l}\text { Num. of } \\
\text { sequences }\end{array}$ & $\begin{array}{l}T^{\text {av }}-T^{\text {obs }} \\
\text { (day) }\end{array}$ & $\begin{array}{l}\text { Forecast } \\
\text { spread (day) }\end{array}$ & $\begin{array}{l}T^{\mathrm{wt}}-\mathrm{T}^{\mathrm{obs}} \\
\text { (day) }\end{array}$ & $\begin{array}{l}\text { Forecast } \\
\text { spread (day) }\end{array}$ & $M^{\text {obs }}$ & $M^{a v}$ & $\begin{array}{l}\text { Forecast } \\
\text { spread }\end{array}$ \\
\hline \multirow[t]{4}{*}{ B7 } & 0.831445 & 5 & 8.8 & 3.6 & 8.9 & 3.6 & 5.1 & 4.79 & 0.47 \\
\hline & & 10 & 4.3 & 6.7 & 4.6 & 6.8 & & 4.76 & 0.48 \\
\hline & & 15 & 1.4 & 8.5 & 1.7 & 8.6 & & 4.75 & 0.47 \\
\hline & & 20 & 3.4 & 9.6 & 3.4 & 9.6 & & 4.75 & 0.46 \\
\hline \multirow[t]{4}{*}{ B8 } & 1.399565 & 5 & -45.0 & 11.9 & -45.0 & 12.0 & 4.8 & 4.78 & 0.45 \\
\hline & & 10 & -45.9 & 13.1 & -45.9 & 13.2 & & 4.77 & 0.45 \\
\hline & & 15 & -46.0 & 14.6 & -46.1 & 14.2 & & 4.77 & 0.45 \\
\hline & & 20 & -46.9 & 18.4 & -46.8 & 15.0 & & 4.76 & 0.45 \\
\hline \multirow[t]{4}{*}{ B9 } & 2.005906 & 5 & 3.9 & 7.3 & 4.9 & 10.9 & 5.2 & 4.79 & 0.43 \\
\hline & & 10 & -4.7 & 12.0 & -2.6 & 19.4 & & 4.78 & 0.42 \\
\hline & & 15 & -13.1 & 16.8 & -8.1 & 27.3 & & 4.77 & 0.42 \\
\hline & & 20 & -22.9 & 23.1 & -12.9 & 33.4 & & 4.78 & 0.43 \\
\hline \multirow[t]{4}{*}{ B10 } & 2.685848 & 5 & 103.2 & 15.5 & 104.6 & 16.0 & 4.9 & 4.80 & 0.42 \\
\hline & & 10 & 80.9 & 32.3 & 87.9 & 33.0 & & 4.78 & 0.42 \\
\hline & & 15 & 69.5 & 38.9 & 82.5 & 41.1 & & 4.79 & 0.42 \\
\hline & & 20 & 56.3 & 31.5 & 77.7 & 35.1 & & 4.79 & 0.43 \\
\hline \multirow[t]{4}{*}{ B11 } & 3.84531 & 5 & -3.5 & 32.2 & -3.6 & 32.2 & 4.8 & 4.71 & 0.42 \\
\hline & & 10 & 11.1 & 46.6 & 5.7 & 46.9 & & 4.74 & 0.42 \\
\hline & & 15 & 30.6 & 61.4 & 19.0 & 62.5 & & 4.78 & 0.41 \\
\hline & & 20 & 56.4 & 83.2 & 33.5 & 86.3 & & 4.80 & 0.41 \\
\hline
\end{tabular}

Table 4 Average error over five events estimated using Eq. (13)

\begin{tabular}{lcll}
\hline & $\begin{array}{l}\text { Num. } \\
\text { of sequences }\end{array}$ & $\begin{array}{l}\text { Average error } \\
\text { of } \text { T }^{\text {av }} \text { (day) }\end{array}$ & $\begin{array}{l}\text { Average error } \\
\text { of } \text { T }^{\mathbf{w t}} \text { (day) }\end{array}$ \\
\hline Groups 1 and 2 & 5 & 57.3 & 57.9 \\
& 10 & 57.5 & 57.3 \\
& 15 & 56.8 & 56.6 \\
Group 2 & 20 & 57.8 & 56.9 \\
& 5 & 50.6 & 51.2 \\
& 10 & 42.0 & 44.5 \\
& 15 & 40.1 & 43.3 \\
& 20 & 42.6 & 43.7 \\
\hline
\end{tabular}

be obtained directly from the observations unless the histories of the stress and slip velocity can be monitored across the entire fault. However, such monitoring is presently impossible. If constraints on the stress and slip velocity can be obtained from the distribution of the seismic slip and stress changes from inversion analysis, the numerical simulation could be improved. In this paper, we changed the selected sequences when each seismic event occurred. If the state just after the $(I-1)$ th event is regarded as the initial condition for the Ith event, changing selection of modeled sequences means changing both the frictional parameters and the initial conditions. Although different initial conditions can be selected for the prepared sets, the initial conditions cannot be newly tuned using information of the $(I-1)$ th event. The development of an assimilation technique is necessary to obtain adequate initial conditions.

The forecast uncertainties could be also due to the complication of afterslip process. That is, fluctuations may affect the occurrence times of the repeaters. Uchida et al. (2005) examined the recurrence intervals of the Kamaishi repeater before the 2011 Tohoku-oki earthquake and found that the acceleration of creep around the repeater advanced the occurrence time. Furthermore, creep deceleration resulted in a longer interval. If the afterslip fluctuation is included in our simulation, the simulation results will likely be easy to fit to the observation. However, such an approach is not used in forecasting. If information on the afterslip fluctuation can be independently obtained from data other than the occurrence time of the repeater, the information would be useful for forecasting.

We attempted to forecast the next event (B12) that has not yet occurred. Tables 5, 6 and Fig. 13 show the forecast results obtained using both groups 1 and 2, and only group 2 , respectively. As scattering of the computed occurrence time increases for later events, the forecast spread of the 12th event is large compared with those of previous events. 
Table 5 Forecast of event B12 using groups 1 and 2

\begin{tabular}{|c|c|c|c|c|c|c|c|}
\hline Event & $\begin{array}{l}\text { Num. } \\
\text { of sequences }\end{array}$ & $\mathrm{T}^{\mathrm{av}}$ (year) & $\begin{array}{l}\text { Forecast spread } \\
\text { (day) }\end{array}$ & $\mathrm{T}^{\mathrm{wt}}$ (year) & $\begin{array}{l}\text { Forecast spread } \\
\text { (day) }\end{array}$ & $M^{\text {av }}$ & $\begin{array}{l}\text { Forecast } \\
\text { spread }\end{array}$ \\
\hline \multirow[t]{4}{*}{ B12 } & 5 & 5.227 & 44.1 & 5.220 & 44.1 & 4.75 & 0.4 \\
\hline & 10 & 5.335 & 58 & 5.294 & 60 & 4.83 & 0.39 \\
\hline & 15 & 5.361 & 80.9 & 5.315 & 82.7 & 4.84 & 0.39 \\
\hline & 20 & 5.360 & 80.3 & 5.319 & 81.7 & 4.87 & 0.39 \\
\hline
\end{tabular}

Table 6 Forecast of event B12 using group 2

\begin{tabular}{llllllcc}
\hline Event & $\begin{array}{l}\text { Num. } \\
\text { of sequences }\end{array}$ & $\mathbf{T}^{\text {av }}$ (year) & $\begin{array}{l}\text { Forecast spread } \\
\text { (day) }\end{array}$ & T $^{\text {wt }}$ (year) & $\begin{array}{l}\text { Forecast spread } \\
\text { (day) }\end{array}$ & $\mathbf{M}^{\text {av }}$ & $\begin{array}{l}\text { Forecast } \\
\text { spread }\end{array}$ \\
\hline B12 & 5 & 5.227 & 44.1 & 5.220 & 44.1 & 4.75 & 0.4 \\
& 10 & 5.262 & 62.1 & 5.255 & 62.1 & 4.78 & 0.39 \\
& 15 & 5.336 & 84.6 & 5.292 & 86.1 & 4.81 & 0.39 \\
& 20 & 5.441 & 120.2 & 5.325 & 127.4 & 4.84 & 0.39 \\
\hline
\end{tabular}
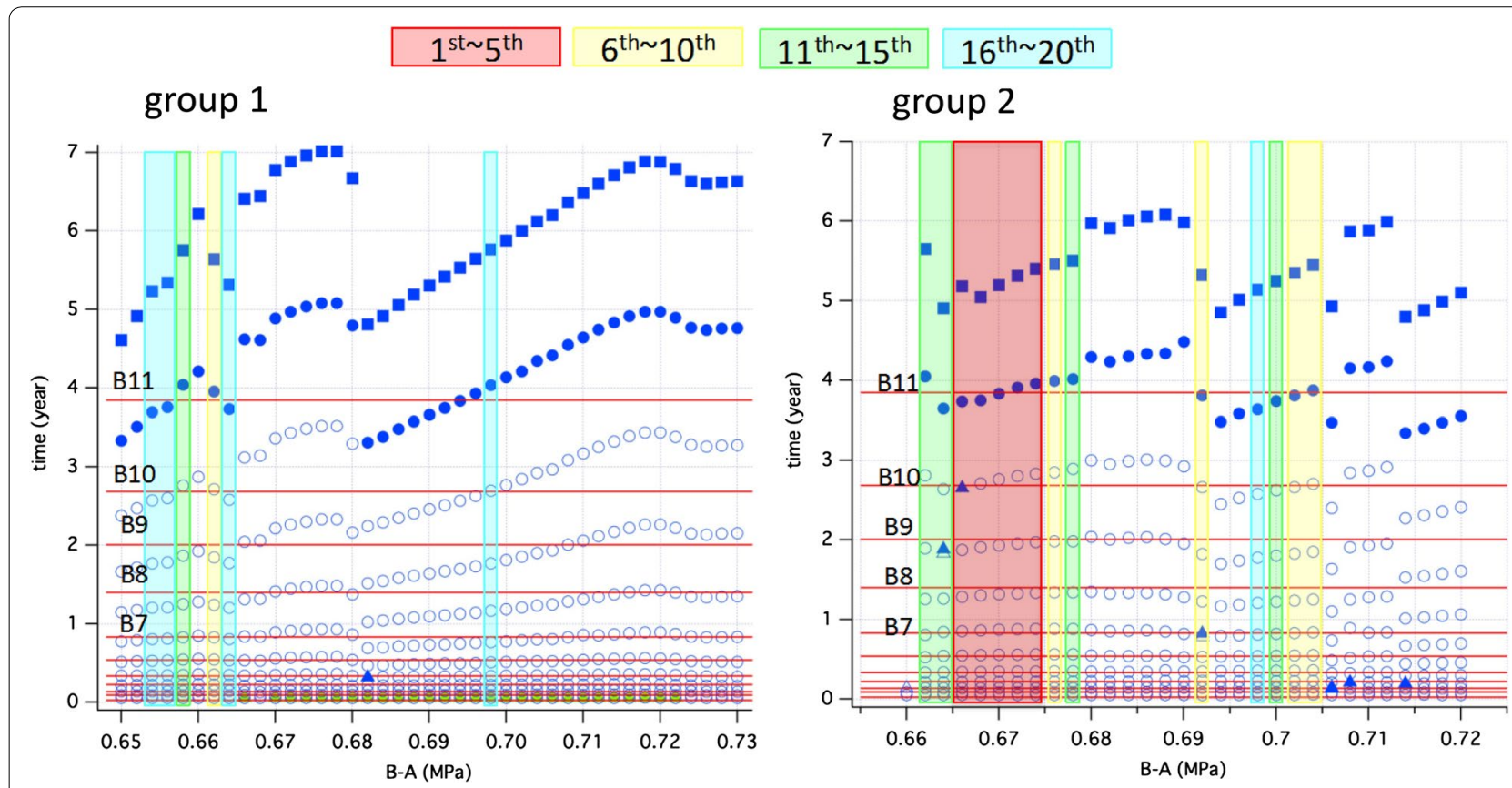

Fig. 13 Same as Fig. 8 for forecasting event B12. Filled squares denote the individual forecasts of the occurrence time of B12

This paper attempted to forecast the occurrences of the Kamaishi repeaters after the 2011 Tohoku-oki earthquake on the basis of numerical simulations using rateand state-depending friction law revised by Nagata et al. (2012) and afterslip process estimated by Fukuda et al. (2013). With a variety of selection in frictional parameters, we found that the ensemble average of the selected sequences seemed useful in providing reasonable forecasts.

\section{Authors' contributions}

NK developed the program code. SY modified the code, conducted the numerical simulation, and drafted the manuscript. JF obtained afterslip by performing inversion of GPS data. All authors read and approved the final manuscript.

\section{Acknowledgements}

We thank C. H. Chan and an anonymous reviewer for insightful reviews. This research was partly supported by the Ministry of Education, Culture, Sports, Science and Technology (MEXT) of Japan, under its Observation and Research Program for Prediction of Earthquakes and Volcanic Eruptions. 


\section{Competing interests}

The authors declare that they have no competing interests.

Received: 15 December 2015 Accepted: 18 April 2016

Published online: 30 April 2016

\section{References}

Barker TW (1991) The relationship between spread and forecast error in extended-range forecasts. J Clim 4:733-742

Chen T, Lapusta N (2009) Rate and state friction laws can explain scaling of small repeating earthquakes. J Geophys Res. doi:10.1029/2008JB005749

DeMets C, Gordon RG, Argus DF, Stein S (1990) Current plate motions. Geophys J Int. doi:10.1111/j.1365-246X.1990.tb06579.x

Dieterich JH (1979) Modeling of rock friction: 1. Experimental results and constitutive equations. J Geophys Res 84:2161-2168

Fukuda J, Kato A, Kato N, Aoki Y (2013) Are the frictional properties of creeping faults persistent? Evidence from rapid afterslip following the 2011 Tohoku-oki earthquake. Geophys Res Lett. doi:10.1002/grl.50713

Hanks TC, Kanamori H (1979) Moment magnitude scale. J Geophys Res 84:2348-2350

Kano M, Miyazaki S, Ito K, Hirahara K (2013) An adjoint data assimilation method for optimizing frictional parameters on the afterslip area. Earth Planets Space 65:1575-1580. doi:10.5047/eps.2013.08.002

Kano M, Miyazaki S, Ishikawa Y, Hiyoshi Y, Ito K, Hirahara K (2015) Real data assimilation for optimization of frictional parameters and prediction of afterslip in the 2003 Tokachi-oki earthquake inferred from slip velocity by an adjoint method. Geophys J Int 203:646-663. doi:10.1093/gji/ggv289

Kato N (2003) Repeating slip events at a circular asperity: numerical simulation with a rate- and state-dependent friction law. Bull Earthq Res Inst Univ Tokyo 78:151-166

Kato N (2004a) A possible effect of an intermediate depth intraslab earthquakes at a subduction zone. Earth planets Space 56:553-561

Kato N (2004b) Interaction of slip on asperities: numerical simulation of seismic cycles on a two-dimensional planar fault with nonuniform frictional property. J Geophys Res 109:B12306. doi:10.1029/2004JB003001
Kuroki H, Ito HM, Yoshida A (2004) Effects of nearby large earthquakes on the occurrence time of the Tokai earthquake-an estimation based on a 3-D simulation of plate subduction- (2004). Earth Planets Space 56:169-178

Matsuzawa T, Igarashi T, Hasegawa A (2001) Regularly occurring small earthquakes off Sanriku, Japan. Tohoku Geophys J 36:263

Matsuzawa T, Igarashi T, Hasegawa A (2002) Characteristic small-earthquake sequence off Sanriku, northeastern Honsyu, Japan. Geophys Res Lett. doi: 10.1029/2001GL014632

Nagata K, Nakatani M, Yoshida S (2012) A revised rate- and state-dependent friction law obtained by constraining constitutive and evolution laws separately with laboratory data. J Geophys Res 117:B02314. doi:10.1029/ $2011 \mathrm{JB} 008818$

Okada M, Uchida N, Aoki S (2012) Statistical forecasts and tests for small interplate repeating earthquakes along the Japan Trench. Earth, Planets and Space 64:703-715. doi:10.5047/eps.2011.02.008

Rice JR (1993) Spatio-temporal complexity of slip on a fault. J Geophys Res 98:9885-9907

Ruina A (1983) Slip instability and state variable friction laws. J Geophys Res 88:10359-10370

Uchida N, Matsuzawa T, Hasegawa A, Igarashi T (2005) Recurrence intervals of characteristic M4.8 \pm 0.1 earthquakes off-Kamaishi, NE Japan-Comparison with creep rate estimated from small repeating earthquake data. Earth Planet Sci Lett 233:155-165

Uchida N, Shimamura K, Matsuzawa T, Okada T (2014) Postseismic response of repeating earthquakes around the 2011 Tohoku-oki earthquake: moment increases due to the fast loading rate. J Geophys Res. doi:10.1002/201 3JB010933

Yamaguchi M, Sakai R, Kyoda M, Komori T, Kadowaki T (2009) Typhoon ensemble prediction system developed at the Japan Meteorological Agency. Monthly Weather Rev. doi:10.1175/2009MWR2697.1

Yoshida S, Kato N, Fukuda J (2015) Numerical simulation of the Kamaishi repeating earthquake sequence: change in magnitude due to the 2011 Tohoku-oki earthquake. Tectonophysics. doi:10.1016/j.tecto.2015.03.012

\section{Submit your manuscript to a SpringerOpen ${ }^{\circ}$ journal and benefit from:}

- Convenient online submission

- Rigorous peer review

- Immediate publication on acceptance

- Open access: articles freely available online

- High visibility within the field

- Retaining the copyright to your article

Submit your next manuscript at $\boldsymbol{\nabla}$ springeropen.com 